\title{
Correlation of Urinary Type-Ii Collagen C Telopeptide (Ctx-Ii) Level With Physical Parameters among Knee Osteoarthritic Patients
}

\author{
G. Majachunglu ${ }^{1}$, L. Suresh Roy ${ }^{2}$, Ak. Joy Singh ${ }^{3}$, Lalvarmawi Florence ${ }^{4}$, \\ Kanmi Ningshen ${ }^{1}$ \\ ${ }^{1}$ Postgraduate Student, Department Of Physiology, RIMS, Imphal, India, \\ ${ }^{2}$ Associate Professor, Department Of Physiology RIMS, Imphal, India, \\ ${ }^{3}$ Prof \& Head, Department Of Physical Medicine \& Rehabilitation RIMS, Imphal, India, \\ ${ }^{4}$ Assistant Professor, Department Of Physiology RIMS, Imphal, India
}

\begin{abstract}
L
Introduction: Osteoarthritis (OA), A Chronic, Degenerative Disorder Of Unknown Cause Characterized By Gradual Loss Of Articular Cartilage, Is The Most Prevalent Disease In Our Society With A Worldwide Distribution And Disabling Locomotors Disease Characterized By Degradation Of Articular Cartilage. Objective: To Estimate The Urinary Level Of Type II Collagen C Telopeptide (CTX-II) Among Osteoarthritic Patients.

Method: This Was A Cross-Sectional Study Conducted In The Departments Of Physiology And Physical Medicine And Rehabilitation, Regional Institute Of Medical Sciences, Imphal Among Osteoarthritic Patients In Manipur During October 2012 To March 2014. Urinary Levels Of C-Terminal Cross-Linking Telopeptide Of Type II Collagen (U-CTX-II) Were Measured By ELISA Kits.

Result: The Concentration Of Uctx-II Was Significantly Higher In OA Patients Compared With Controls. It Was Observed That The Levels Were Found To Be Higher Among The Female Patients. There Was No Correlation Of U-CTX-II With Any Physical Parameters Like Age, Height And Weight.
\end{abstract}

Conclusion: These Findings Indicate That The Bone Resorption Process Is Higher In Osteoarthritic Patients.

Keywords: Cartilage, Bone, Resorption, Uctx-II, Osteoarthritis, ELISA.

\section{Introduction}

Osteoarthritis (OA) Is Defined As A Heterogeneous Group Of Conditions That Lead To Joint Symptoms And Which Are Associated With Defective Integrity Of Articular Cartilage, In Addition To Changes In The Underlying Bone And At The Joint Margins. ${ }^{(1)}$ Knee OA Is Not A Localized Disease Of Cartilage Alone But Is Considered As A Chronic Disease Of The Whole Joint, Including Articular Cartilage, Meniscus, Ligament, And Peri-Articular Muscle That May Result From Multiple Pathophysiological Mechanisms. ${ }^{(2)}$ It Is The Most Common Joint Disease, Affecting About 10\% Of The Population Over The Age Of 50 Yrs. $^{(3)}$ The Proportions Of People Affected With Symptomatic Knee OA Is Likely To Increase Due To The Aging Of The Population And The Rate Of Obesity Or Overweight In The General Population. ${ }^{(2)}$ And It Is Becoming An Increasingly Important Disease In Especially Aging Population. ${ }^{(4)}$ A Recent World Health Organization Report On The Global Burden Of Disease Indicated That Knee OA Is Likely To Become The Fourth Most Important Global Cause Of Disability In Women And The Eighth In Men. Although OA Can Affect Any Synovial Joint, OA In Knee Joints Has The Highest Prevalence Rate ${ }^{(5)}$ And Epidemiological Studies Suggest That The Knee Is The Most Important And Common Site Causing Pain And Disability. ${ }^{(3)}$

Diagnosis Of OA Is Essentially Based On Clinical History And Radiological Findings. The Clinical Symptoms Are Joint Pain, Stiffness, Limitation Of Range Of Motion And Crepitus. Joint Effusion And Variable Degrees Of Local Inflammation Can Also Be Seen. ${ }^{(4)}$ Risk Factors Such As Age, Sex, Trauma, Overuse, Genetics, And Obesity Can Each Make Contributions To The Process Of Injury In Different Compartments Of The Joint. Such Risk Factors Can Serve As Initiators That Promote Abnormal Biochemical Processes Involving The Cartilage, Bone, And Synovium, Which Over A Period Of Years Result In The Characteristic Features Of $\mathrm{OA}^{(6)}$ And In Advanced Stages, Joint Contractures, Muscle Atrophy And Limb Deformity. ${ }^{(7)}$

Many Biomarkers Have Been Investigated To Study The Prognosis And Pathogenesis Of Osteoarthritis. ${ }^{(8)}$ One Such Biomarker Is C-Telopeptide Fragments Of Type II Collagen (CTX-II) Which Is Created During Articular Cartilage Breakdown And Excreted In Urine. Urinary CTXII Has Been Shown To Be Elevated In Correlation With The Presence And Severity Of Knee OA ${ }^{(9,10)}$ Degradation Of Type II Collagen May Be Measured In Urine By Testing For Fragments Of The Helical (Helix-II) Or C-Telopeptide Regions 
(CTX-II), Which Are Localized Primarily To Hyaline Cartilage. CTX-II Has Been More Extensively Studied, And Is Raised In Osteoarthritic Patients Compared With Controls And Predicts The Severity And Progression Of OA Of The Knee. ${ }^{(8)}$ CTX-II Potentially Represents A Specific Marker Of Cartilage Degradation That May Be Suitable For The Clinical Monitoring Of OA. ${ }^{(11)}$ High Levels Of C-Terminal Crosslinking Telopeptide Of Type II Collagen (CTX-II) Have An 8-Fold Increased Risk Of OA Progression. ${ }^{(12)}$ However, Very Few Studies Have Measured Type II Collagen Fragments. ${ }^{(13)}$ Biochemical Markers Are Relatively Inexpensive And Easy To Measure, Allowing Repeated, Frequent Measurements. In Addition, Biochemical Markers May Provide Useful Information About Current Pathologic Processes At The Time Of Assay. ${ }^{(14)}$

Our Study Is Perhaps The First Kind To Examine Biochemical Markers Among Osteoarthritic Patients In Manipur Over The Age Range Of 50 Years And Above. This Study Was Undertaken To Estimate The Urinary Level Of Type II Collagen C Telopeptide (CTX-II) Among Osteoarthritic Patients And Find The Correlation Of Uctx-II With Physical Parameter Like Age, Height And Weight.

\section{Study Design}

\section{Materials And Methods}

This Was An Observational And Cross-Sectional Study Conducted In The Departments Of Physiology And Physical Medicine And Rehabilitation (PMR), Regional Institute Of Medical Sciences (RIMS), Imphal. This Study Was Conducted During The Period Of One And Half Years (October, 2012 To March, 2014).

\section{Study Population}

The Study Was Done On 92 Subjects Who Were Divided Into Two Groups - A Study Group Consisting Of 46 Patients Who Met The American College Of Rheumatology ${ }^{(1)}$ Criteria For Knee Osteoarthritis (OA) And Attended The Out-Patient Department Of PMR, RIMS, Imphal. Another Control Group Of 46 Subjects Were Chosen From Healthy Individuals Who Were Age And Sex-Matched Without Any Clinical Evidence Of Knee Osteoarthritis.

\section{Inclusion Criteria}

Adult Male Or Female With Age > 50 Years, Clinical Confirmation OA Of The Knee For At Least 3 Months Prior To The Study, Pain In Or Around The Knee Most Of The Time, Morning Stiffness Of $<30$ Minutes, No Intra-Articular Lesion Requiring Surgery (E.G. Of Meniscus, Cartilage Or Ligament) Or Likely To Require Surgery During The Study Period.

\section{Exclusion Criteria}

Patients Having Any Current Or Previous Inflammatory Joint Diseases, Patients Who Had Acute Major Trauma, Patients Having Treatment Within 3 Months Before Inclusion With Any Drugs Which May Interfere With The Test

\section{Study Variables}

Uctx-II Was Estimated By Using An ELISA Kit (Human CTX-II ELISA Kit, Sunred Biotechnology, Shanghai) Which Is Based On The Competitive Binding Of A Monoclonal Antibody To Urinary Fragments Of Type II Collagen Or To Biotinylated, Synthetic Peptides Bound To The Surface Of Microtitre Plates Coated With Streptavidin.

\section{Ethics Approval}

All The Subjects Were Informed About The Nature Of The Study And Those Who Agreed To Participate Were Asked To Sign The Informed Consent Form. The Approval Of The Institutional Ethics Committee Was Taken.

\section{Statistical Analysis}

All Data Were Entered And Analysis Performed Using Statistical Package Of Social Sciences (SPSS) Software Version 16 (SPSS, Inc, An IBM Company, Chicago, Illinois, US). Descriptive Statistics Like Mean And Standard Deviation Were Calculated. The Student-T Test Was Used To Compare The Mean Values Of The Various Variables Between Patient Group And Healthy Control Group.

\section{Results And Observations}

The Present Study Was Conducted On 92 Subjects, Out Of Which 46 Were Patients Who Were Suffering From Osteoarthritis Which Met The American College Of Rheumatology Criteria For Knee Osteoarthritis Belonging To Both Sex And Attended The Out-Patient Department Of Physical, Medicine \& Rehabilitation, Regional Institute Of Medical Sciences (RIMS), Imphal And Another 46 Were Normal Healthy 
Subjects Belonging To Both Sex. The Study Was Carried Out During The Period Of One And Half Years (October, 2012 To March, 2014).

Table 1 Show The Mean Ages As 55.8 And 59.58 Years Among The Male And Female Osteoarthritic (OA) Patients Respectively Which Was Found To Be Significant, Whereas The Mean Ages Were 53.23 And 52.0 Years Among The Male And Female Healthy Groups Respectively. Overall, The Male Were Taller And Heavier Than Their Counterparts In Both Groups. It Also Shows The Other Demographic Profile Like Height And Weight, But The Duration Of The Disease Is Presented Only In Case Of OA Patients. It Shows That The Mean Heights In Male And Female OA Subjects Were Significant. The Mean Weights Of Both Healthy Subjects Were $62.81+4.6 \mathrm{Kg}$ And $59.56+4.8 \mathrm{Kg}$ In Males And Females Respectively, Whereas The Mean Weights Of OA Subjects Were $61.07 \pm 3.7 \mathrm{Kg}$ And $54.61 \pm 3.6 \mathrm{Kg}$ In Males And Females Respectively. The Mean Duration Of The Osteoarthritis Was 8.8 \pm 6.4 And 7.42 \pm 3.0 Months In Males And Females Respectively.

Table 1: Socio- Demographic Profile Of The Study Subjects (In Mean \pm SD)

\begin{tabular}{lcccc}
\hline & Male $(\mathrm{n}=36)$ & \multicolumn{3}{c}{ Female $(\mathrm{n}=56)$} \\
\hline Characteristics & $\begin{array}{c}\text { Healthy } \\
(\mathrm{n}=21)\end{array}$ & $\begin{array}{c}\text { OA } \\
(\mathrm{n}=15)\end{array}$ & $\begin{array}{c}\text { Healthy } \\
(\mathrm{n}=25)\end{array}$ & $\begin{array}{c}\text { OA } \\
(\mathrm{n}=31)\end{array}$ \\
\hline Age (in years) & $53.24 \pm 3.9$ & $55.8 \pm 8.5$ & $52.0 \pm 3.3$ & $59.58 \pm 9.4$ \\
Height (in cm) & $161.2 \pm 4.0$ & $160.8 \pm 4.0 * *$ & $154.24 \pm 2.9$ & $152.7 \pm 2.5 * *$ \\
Weight (in kg) & $62.81 \pm 4.6$ & $61.07 \pm 3.7 * *$ & $59.56 \pm 4.8$ & $54.61 \pm 3.6 * *$ \\
Duration (in months) & - & $8.8 \pm 6.4$ & - & $7.42 \pm 3.0$ \\
\hline
\end{tabular}

N.B: ** Indicates Significance At 0.01 Levels (2-Tailed)

Table 2 Documents The Value Of The Biomarkers In Both Sexes Among The Healthy And OA Patients. The Mean Values Of Uctx-II Levels In Female And Male OA Subjects Were Found To Be $587.77 \pm 165.2$ And $520.53 \pm 81 \mathrm{Ng} / \mathrm{Mmol}$ Respectively, Whereas The Mean Values Of Uctx II Levels In Female And Male Healthy Subjects Were 298.20 \pm 68.66 And 300.62 $\pm 40.43 \mathrm{Ng} / \mathrm{Mmol}$ Respectively. So, The Levels Of Uctx-II Were Higher Among The Females In Both Groups.

Table 2: Biomarkers Profile Among The Subjects

\begin{tabular}{lcccc}
\hline \multicolumn{3}{c}{ Male $(\mathrm{N}=36)$} & \multicolumn{2}{c}{ Female $(\mathrm{N}=56)$} \\
\hline Characters & $\begin{array}{c}\text { Healthy } \\
(\mathrm{N}=21)\end{array}$ & $\begin{array}{c}\text { OA } \\
(\mathrm{N}=15)\end{array}$ & $\begin{array}{c}\text { Healthy } \\
(\mathrm{N}=25)\end{array}$ & $\begin{array}{l}\text { OA } \\
(\mathrm{N}=31)\end{array}$ \\
\hline Uctx-II & $300.62 \pm 40.43$ & $520.53 \pm 81^{* *}$ & $298.20 \pm 68.66$ & $587.77 \pm 165.2^{* * *}$ \\
$(\mathrm{Ng} / \mathrm{Mmol} \mathrm{Cr})$ & & & & \\
\hline
\end{tabular}

$\mathrm{NB}$ ** Indicate High Significant At 0.01 (2- Tailed)

Table 3.Correlation Between Uctx-II \& Other Parameters Among OA Subjects

\begin{tabular}{lcccc}
\hline Male $(\mathrm{N}=15)$ & & Female $(\mathrm{N}=31)$ & & \\
\hline Variables & R- Value & P-Value & R-Value & P-Value \\
\hline -Age & -0.386 & 0.155 & -0.065 & 0.728 \\
\hline Weight & -0.295 & 0.286 & -0.108 & 0.563 \\
\hline Height & -0.283 & 0.306 & -0.166 & 0.372 \\
\hline Duration & -0.059 & 0.836 & 0.635 & $0.000^{* * *}$ \\
\hline
\end{tabular}

N.B : ** Indicates Significant At 0.01 Level (2-Tailed).

Table 4: Correlation Between Uctx-II And Other Parameters Among Healthy Subjects

\begin{tabular}{lcccc}
\hline & \multicolumn{2}{c}{ Male $(\mathrm{N}=21)$} & \multicolumn{2}{c}{ Female $(\mathrm{N}=25)$} \\
\hline Variables & R-Value & P-Value & R-Value & P-Value \\
\hline Age & 0.134 & 0.561 & -0.194 & 0.352 \\
\hline Weight & -0.321 & 0.156 & -0.053 & 0.803 \\
\hline Height & -0.186 & 0.149 & 0.393 & 0.052 \\
\hline
\end{tabular}

Table 3 Shows The Correlation Between Uctx-II And Other Parameters Like Age, Weight, Height And Duration Of The Disease Among OA Subjects In Both The Sexes. Among OA Male Subjects, It Was Seen That There Was No Correlation With Any Of The Parameters. The Value Of Pearson Correlation Coefficient (R) Between Uctx-II And Age Was -0.386, And The P-Value Was 0.155 Which Is Insignificant. The R Value 
Between Uctx-II And Weight Was -0.295, And The P-Value Was 0.286 Which Is Insignificant. The R Value Between Uctx-II And Height Was -0.283, And The P-Value Was 0.306 Which Is Insignificant Again. Lastly, The R Value Between Uctx-II And Duration Of Disease Was - 0.059, Whereas The P-Value Was 0.836 Which Is Also Insignificant.

And Among The Female OA Subjects, The Correlation Between Uctx-II And Other Parameters Shows A Significant Positive Correlation Between Uctx-II And The Duration Of The Disease Only, Where The Values Of R And P Were 0.635 And 0.000 Respectively. The Correlation Between Uctx-II And Age Or Weight Or Height Was Negative Where $\mathrm{R}=-0.065$ And $\mathrm{P}=0.728$. In Case Of The Correlation Between Uctx-II And Weight, It Was Negative Again Where $\mathrm{R}=-0.108$ And $\mathrm{P}=0.563$. The Correlation Between Uctx-II And Height Was Negative Again Where $\mathrm{R}=-0.166$ And $\mathrm{P}=0.372$.

Table 4 Shows The Correlation Analysis Between Uctx-II And Other Parameters Among The Healthy Male Subjects. The Analysis Revealed No Significant Correlation, Because There Is Positive Correlation Of Uctx-II With Age $(\mathrm{R}=0.134$ And $\mathrm{P}=0.561)$. On The Other Hand, There Is Negative Correlation Of Uctx-II With Weight $(\mathrm{R}=-0.321$ And $\mathrm{P}=0.156)$ And Height $(\mathrm{R}=-0.186$ And $\mathrm{P}=0.419)$ Which Were Also Insignificant. And The Correlation Between Uctx-II And Other Parameters Among Healthy Female Subjects Revealed A Moderate Correlation Between Uctx-II And Cartilage Volume In Healthy Female Subjects, Where The Values Of R And P Are 0.577 And 0.003. On The Other Hand, There Is No Significant Correlation Of Uctx-II With The Remaining Parameters Like Age, Weight And Height.

\section{Discussion}

The Complexity Of Osteoarthritis Makes Development Of Biomarkers Challenging, Since On One Hand, There Are Many Onset Factors Like Genetics, Trauma, Biomechanics And Exercise, And Different Pathological Mechanisms May Be Involved In Different Phases Of Osteoarthritis. The Diagnostic And Prognostic Values Of One Biomarker Was Evaluated Which Is Of Current Interest Throughout The World. The Biomarker Is The CTX-II Biomarker Which Is Targeted To The Urinary Excretion Of CTX-II. In The Present Study Population, We Have Assessed Uctx-II Levels In Healthy And OA To Examined Its Variation With Age, Weight, Height And Duration In Case Of OA.

In The Present Study, The Mean Ages Were 55.8+8.5 And 59.58+9.4 Years Among The Male And Female Osteoarthritic Patients Respectively, While The Mean Ages Of Healthy Subjects Were 53.24+3.9 And 59.58+9.4 Years In Male And Female Respectively. The Age Dependent Variation In Mean CTX II Concentration Showed Increased Level In OA Indicates An Increase In Cartilage Degradation In OA Particularly More In Female OA. This Finding Could Reflex The Well Known Increase In Prevalence With Age Of OA. ${ }^{(1)}$ The Comparison Of Correlation Between CTX II And Age Show That There Is Weak Correlation Even Though There Is Marked Increased In OA Particularly In Women Which Is In Accordance With The Findings By Mouritzen Et Al In Which CTX II Concentration Was Demonstrated Slightly Increase Value With Increase Age In Both Sexes From 55 Years And Upwards.

In The Present Study, The Mean Weights Were 61.07 \pm 3.7 And 54.61+3.6 Kg Among Male And Female OA Subjects Respectively, Whereas The Mean Weights Among Healthy Male And Female Subjects

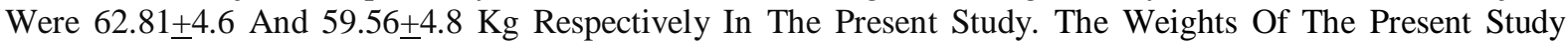
Group Were Found To Be Significant In All The Group Except Among The Healthy And Patients Of Same Sex. Cross Sectional As Well As Longitudinal Studies Have Shown That Being Overweight Is A Risk Factor For The Development Of Knee OA. ${ }^{(15)}$ Subjects With A BMI $\geq 25 \mathrm{Kg} / \mathrm{M}^{2}$ (Overweight) Had Significantly Higher CTX-II Concentrations Than Those With A BMI $<25 \mathrm{Kg} / \mathrm{M}^{2}$. These Findings Do Not Provide Conclusive Evidence On The Role Of BMI In Influencing CTX-II Concentrations, But Do Suggest That BMI Is A Contributing Pathogenic Factor In Cartilage Degradation. ${ }^{(11)}$

In The Present Study, The Mean Duration Of The Disease Was 8.8 \pm 6.4 Months Among Male Subjects And It Was 7.42 \pm 3.0 Months Among Female Subjects. These Findings Were Different From Other Studies, Whereas The Duration Of The Disease Was Reported By Garnero P Et Al ${ }^{(16)}$ As 6.6 Years. In The Present Study, The Mean Levels Of Uctx-II Were 520.53 \pm 81 And $587.77 \pm 165.2 \mathrm{Ng} / \mathrm{Mmol}$ Creatinine Among Male And Female Patients Respectively And The Mean Levels Of Healthy Male And Female Subjects Were

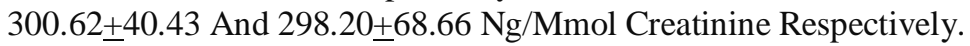

In This Study, We Observed Increased Urinary CTX-II Levels In Patients With Knee OA This Observation Was Consistent With Previous Reports. ${ }^{(12,17)}$ Jung M Et Al ${ }^{(18)}$ Also Reported That The Concentration Of CTX-II Was Significantly Higher In OA Patients Compared With Controls (527 Vs.190 $\mathrm{Ng} / \mathrm{Mmol}, \mathrm{P}<0.001)$. Garnero P Et Al ${ }^{(12)}$ Again Reported That The Median Uctx-II Levels Was $432 \mathrm{Ng} / \mathrm{Mmol}$ In Their Study Population, And Ofluoglu D ${ }^{(4)}$ And His Associates Confirmed The Association Of Increased Uctx-II Levels With Rapidly Development Osteoarthritis. Ishijima M Et Al ${ }^{(19)}$ Stated In Their Study That UctxII Increased With The Onset Of Osteoarthritis. Rotterud JH Et Al ${ }^{(9)}$ Found At Baseline The Mean CTX-II Concentration Of The Patients With A Focal Cartilage Lesion Of The Knee Was 579 Ng/Mmol And Healthy 
Control Individuals Had A Mean CTX-II Concentration Of 129 Ng/Mmol. The Findings Were Almost Similar Findings Among The Patients. Furthermore, In A Recent Study Of Reijman Et Al ${ }^{(17)}$ It Was Shown That Subjects In The Highest Quartiles Of UCTX-II Levels Had A High Increased Risk To Have OA At The Knee.

The Important Findings In This Study Was That, Disease Progression Was Associated With Higher Levels Of CTX-II Suggesting Active Degradation Of Type II Collagen During The Course Of Progression. ${ }^{(3)}$ It Was Shown In GARP Study, That ROA Scores Of The Hip, Knee, Hand And Facet Joints Independently Contributed To The UCTX-II Levels, Whereas Spinal DD Did Not. ${ }^{(20)}$

\section{Limitation Of The Study}

The Present Study May Not Be Able To Throw A Proper Diagnostic And Prognostic Value In Understanding The Complexity Of The Disease Osteoarthritis, Since It Was A Cross-Sectional Study Which Was Focused On Finding Out The Correlation Of One Biomarker Of Osteoarthritis With Biological Profiles Like Age, Weight And Height. Furthermore, There Is A Need For Study Among Larger Population Study, So That Specific Roles Of The Biomarkers Can Be Studied In A More Elaborate Manner.

\section{Conclusions}

Osteoarthritis Remains A Disease Of Various Complexities, So It Is Unlikely That A Single Biomarker Will Be Able To Indicate The Diagnostic And Prognostic Values Of The Disease Condition. The Urinary Biomarker (CTX-II) Levels Can Be Used To Understand The Pathogenesis Of The Disease Osteoarthritis In A Select Group Of Population Or Group. The Relationship Of CTX-II With Age Among Osteoarthritic Subjects Needs To Be Stressed In Future For Use As A Diagnostic Marker. Further, More Elaborate And Detailed Study Need To Be Conducted To Further Understand The Role Of These Biomarkers. A Validated And Reproducible Assay Of Uctx-II, Representing Degradation Of Mature Matrix Molecules, May Therefore Be Of Value For Monitoring The Progression And Treatment Of Human Joint Disease.

\section{Acknowledgement}

We Would Like To Acknowledge The Grant Support Given By DBT Nodal Cell For Medical Colleges And Biomedical Research Institutes Of North East India NAPAAM, Tezpur Assam - 784 028, INDIA In The Completion Of This Study.

\section{References}

[1]. Altman R, Asche E, Bloch D, Bole G, Borenstein D, Brandt K, Et Al. Development Of Criteria For The Classification And Reporting Of Osteoarthritis. Classification Of Osteoarthritis Of The Knee. Arhtritis Rheum Aug 1986; 29(8): 1039-49.

[2]. Heidari B. Knee Osteoarthritis Prevalence, Risk Factors, Pathogenesis And Features: Part I. Caspian J Intern Med 2011; 2(2):205212 .

[3]. Sharif M, Kirwan J, Charni N, Sandell LJ, Whittles C, Garnero P. A 5 Year Longitudinal Study Of Type II A Collagen Synthesis And Total Type II Collagen Degradation In Patients With Knee Osteoarthritis-Association With Disease Progression. Rheumatol 2007; 46: 938-943.

[4]. Ofluoglu D, Ofluoglu O. Assessment Of Disease Activity And Progression Of Osteoarthritis With Using Molecular Markers Of Cartilage And Synoviumturnover. Curr Rheumatol Rev 2005; 1: 29-32.

[5]. Murphy L, Schwartz TA, Helmick CG, Et Al. Lifetime Risk Of Symptomatic Knee Osteoarthritis. Arthritis Rheum 2008; 59:12071213 .

[6]. Garnero P, Delmas PD. Biomarkers In Osteoarthritis. Curr Opin Rheumatol Sept 2003; 15 (5): $641-646$.

[7]. Abramson SB, Attur M. Developments In The Scientific Understanding Of Osteoarthritis. Arthritis Res Ther May 2009; 11: 227.

[8]. Lotz M, Martel-Pelletier J, Christiansen C, Brandi ML, Bruyère O, Chapurlat R, Et Al. Value Of Biomarkers In Osteoarthritis: Current Status And Perspectives. Ann Rheum Dis 2013;0:1-8.

[9]. Rotterud JH, Reinholt FP, Beckstrom KJ,Risberg MA And Aroen A. Relationshi Between CTX-II And Patient Characteristics, Patientreported Outcome, Muscle Strength, And Rehabilitation In Patients With A Focal Cartilage Lesion Of The Knee: A Prospective Exploratory Cohort Study Of 48 Patients. BMC Musculoskeletal Disorders 2014; 15:99.

[10]. Pollard TCB, Gwilym SE, Carr AJ. The Assessment Of Early Osteoarthritis. J Bone Joint Surg 2008; 90-B: 411-21.

[11]. Mouritzen U, Christgau S, Lehmann H-J, Tanko LB, Christiansen C. Cartilage Turnover Assessed With A Newly Developed Assay Measuring Collagen Type II Degradation Products: Influence Of Age, Sex, Menopause, Hormone Replacement Therapy, And Body Mass Index. Ann Rheum Dis 2003; 62: 332-336.

[12]. Garnero P, Ayral X, Rousseau JC, Christgau S, Sandell LJ, Dougados M, Et Al. Uncoupling Of Type II Collagen Synthesis And Degradation Predicts Progression Of Joint Damage In Patients With Knee Osteoarthritis. Arthritis Rheum 2002; 46(10): 26132624.

[13]. Garnero P, Rousseau JC, Delmas PD. Molecular Basis And Clinical Use Of Biochemical Markers Of Bones, Cartilage And Synoivium In Joint Diseases. Arthritis Rheum May 2000; 43(5): 953-968.

[14]. Davis CR, Karl J. Can Biochemical Markers Serve As Surrogates For Imaging In Knee Osteoarthritis. Arthritis Rheum Dec 2007; 56 (12): 4038-4047.

[15]. Felson DT, Chaissan CE. Understanding The Relationship Between Body Weight And Osteoarthritis. Baillieres Clin Rheumatol 1997;11: 671-81.

[16]. Ganero P, Peterfy C, Zaim S, Schoenharting M. Bone Marrow Abnormalities On Magnetic Resonance Imaging Are Associated With Type II Collagen Degradation In Knee Osteoarthritis. Arthritis Rheum Sept 2005; 52(9): 2822-2829.

[17]. Reijman M, Hazes JMW, Bierma-Zeinstra SMA, Koes BW, Christgau S, Christiansen C, Et Al. A New Marker For Osteoarthritis: Cross- Sectional And Longitudinal Approach. Arthritis Rheum Aug 2004; 50(8): 2471-2478. 
[18]. Jung M, Christgau S, Lukoschek M, Henriksen D, Richter W. Increased Urinary Concentration Of Collagen Type II C-Telopeptide Fragments In Patients With Osteoarthritis. Pathobiology 2004; 71:70-76.

[19]. Ishijima M, Watery T, Naito K, Kaneko H, Futami I, Ishida KY, Et Al. Relationship Between Biomarkers Of Cartilage, Bone, Synovial Metabolism And Knee Pain Provide Insights Into The Origin Of Pain In Early Knee Osteoarthritis. Arthritis Res Ther 2011; 13: R22.

[20]. Meulenbelt I, Kloppenburg M, Kroon HM, Houwing-Duistermaat JJ, Garnero P, Hellio, Le Et Al. Urinary CTX-II Levels Are Associated With Radiographic Subtypes Of Osteoarthritis In Hip, Knee, Hand, And Facet Joints In Subject With Familial Osteoarthritis At Multiple Sites: The GARP Study. Ann Rheum Dis Mar 2006; 65(3): 360-65. 